\title{
IMPLEMENTASI KEBIJAKAN KARTU INDONESIA PINTAR DALAM UPAYA PEMERATAAN PENDIDIKAN DI SD NEGERI BADAL II TAHUN AJARAN 2016/2017
}

\author{
Desi Putri Budiarti \\ Jurusan Tarbiyah Program Studi Pendidikan Agama Islam STAIN Kediri
}

\begin{abstract}
Abstrak: salah satu masalah yang paling penting untuk segera diselesaikan di Indonesia adalah masalah pendidikan, khususnya pada masalah pemerataan penddikan di Indonesia itu sendiri. Dengan demikian, upaya pemerintah dalam melakukan pemerataan pendidikan di Indonesia salah satunya adalah melalui kebijakan kartu Indonesia pintar. Penelitian ini bertujuan untuk meneliti implementasi kebijakan kartu Indonesia pintar dalam upaya pemerataan pendidikan. Pendekatan penelitian yang digunakan adalah kualitatif dengan jenis studi kasus. Objek penelitian ini adalah SD Negeri Badal II Badal-Ngadiluwih. Teknik pengumpulan data dalam penelitian ini menggunakan observasi, wawancara, dan dokumentasi. Dalam wawancara peneliti melibatkan kepala sekolah, seorang guru pengurus kebijakan kartu Indonesia pintar, peserta didik penerima kartu Indonesia pintar serta orang tua peserta didik penerima kartu Indonesia pintar.Teknik analisis data dalam penelitian ini menggunakan model interaktif Miles dan Huberman, yaitukondensasi data, penyajian data, penarikan kesimpulan. Keabsahan data menggunakanuji kredibilitas (melalui triangulasi sumber dan teknik), uji transferability (melalui penyusunan hasil penelitian secara rinci, jelas, sistematis dan dapat dipercaya), uji dependability (melalui audit keseluruhan proses penelitian), dan uji confirmability (melalui publikasi hasil peneltian). Hasil dari penelitian menunjukkan implementasi kebijakan kartu Indonesia pintar melalui buku pedoman pelaksanaan kartu Indonesia pintar, maka dapat di ukur melalui lima aspek, yaitu sasaran, besaran dana, pemanfaatan dana, mekanisme pengambilan dana KIP serta tugas dan tanggung jawab sekolah. Adapun implementasi kebijakan kartu Indonesia pintar dalam upaya pemerataan pendidikan, maka dapat dilihat dari dua aspek penting dalam pemerataan pendidikan, yaitu equality dan equity. Selain itu, sosialisasi dari kebijakan kartu Indonesia pintar.
\end{abstract}

Kata kunci: Kebijakan, KIP, equity 
Pendidikan merupakan aspek penting yang dianggap sangat menentukan tingkat kemampuan seseorang dalam menghadapi kehidupan. Melalui pendidikan yang mencukupi, kita dapat hidup dengan layak seperti yang diharapkan. Tentunya harapan manusia dimasa yang akan datang adalah hal yang baik, yaitu keadaan dimana kehidupan kita lebih baik dari keadaan sekarang. Penyelenggaraan pendidikan dimaksudkan untuk memberikan pencerahan dan sekaligus perubahan pola hidup kepada peserta didik. (Saroni, 2013) menyatakan bahwa pencerahan diperlukan sebagai satu usaha sadar untuk menjadikan kita sebagai sosok penting dalam kehidupan dan perubahan yang dimaksud adalah untuk mempersiapkan kita sebagai sosok yang mampu menghadapi setiap perubahan dalam kehidupan.

Menurut UU Nomor 32 Tahun 2004 dan PP 25 Tahun 2005, maka semua warga negara Indonesia berhak mendapatkan pendidikan dan pengajaran tanpa terkecuali, baik "orang kaya" maupun "orang miskin" dan masyarakat perkotaan maupun pedesaan (terpencil). Lebih lanjut lagi sebagaimana diamanatkan oleh UUD 1945, yaitu pemerintah wajib bertanggung jawab dalam mencerdaskan kehidupan bangsa dan memajukan kesejahteraan umum.

Berdasarkan UU Nomor 32 Tahun 2004 dan PP 25 Tahun 2005 serta UUD 1945, maka semua warga negara Indonesia berhak mendapatkan pendidikan, akan tetapi jika dilihat dari realita yang ada belum semua warga negara Indonesia mampu mengenyam pendidikan karena terkendala oleh masalah kemiskinan. Kemiskinan dan pendidikan adalah dua aspek yang memiliki kaitan sangat erat apabila digabungkan dengan kesejahteraan yang ada di masyarakat. Kemiskinan menyebabkan terbatasnya masyarakat untuk mengakses pendidikan, sedangkan pendidikan bertujuan untuk membantu masyarakat keluar dari jeratan kemiskinan yang mereka hadapi. Kemiskinan inilah yang menjadi salah satu penyebab pemerataan pendidikan kurang terlaksana dan sebagai salah satu isu masalah pendidikan di Indonesia.
(Supeno,1999),menyatakan bahwa pendidikan yang dulunya begitu mulia, yakni melepaskan rakyat dari cengkeraman kemelaratan, kini telah menjadi alat dari sistem masyarakat kapitalis. Pendidikan hanyalah milik mereka yang berduit, dan mereka yang berasal dari kelas menengah dan atas. Pendidikan telah menjadi barang mewah, dengan harga yang begitu mahal. Pernyataan tersebut diperkuat dengan adanya permasalahan pendidikan yang terjadi baru-baru ini. Tepatnya di daerah Kediri pada salah satu sekolah jenjang sekolah menengah atas, yaitu SMAN 6 Kota Kediri. Dilansir dari Andhika Dwi-DetikNews (Senin 23 Oktober 2017, 11:35 WIB), ratusan pelajar SMAN 6 Kota Kediri turun ke jalan. Mereka menuntut kepala sekolah (kasek) menurunkan pembayaran SPP. Para pelajar berkumpul sejak pukul 07:00 WIB, di halaman sekolah, Jalan NgasinanRejomulyo Kota Kediri. Mereka membawa poster dan berteriak agar pihak sekolah menurunkan pembayaran SPP. Aksi ini sudah dilakukan para pelajar sebanyak tiga kali. Isi poster diantaranya, "Tolak Kepala Sekolah SMAN 6 Menyalahgunakan Jabatan", "Sekolah Termahal", "Tolak Kepala Sekolah serta turunkan SPP sekarang juga!" teriak Pramudia Hasbi, salah satu pelajar kelas XII di lokasi, Senin (23/10/2017).

Memahami akan hal itu, upaya pemerintah untuk memberikan kesempatan seluas-luasnya kepada masyarakat agar memperoleh layanan pendidikan yaitu salah satunya melalui program kartu Indonesia pintar. Program tersebut diharapkan dapat membangun generasi yang unggul dan masyarakat generasi muda mendapatkan pendidikan yang layak. Kebijakan kartu Indonesia pintar merupakan program pemerintah yang diluncurkan sebagai wujud upaya pemerataan pendidikan di Indonesia. Apabila implementasi kebijakan kartu Indonesia pintar tersebut tepat pada sasaran, maka upaya pemerataan pendidikan di Indonesia akan segera terwujud.

Dalam hal ini menurut (Edward, 1980), terdapat empat aspek dalam pengimplementasian suatu kebijakan yakni, dari segi komunikasi, sumber daya, 
disposisi, dan struktur birokrasi. Namun titik tumpu terberat dalam penelitian ini adalah pada segi komunikasi, yaitu pada sosialisasi kebijakan kartu Indonesia pintar. Hal ini karena peneliti merasa bahwa sosialisasi sangat perlu dilakukan agar para pelaku kebijakan dapat mengetahui, memahami apa yang menjadi isi, tujuan, arah, kelompok sasaran (target groups) kebijakan supaya para pelaku kebijakan dapat mempersiapkan dengan benar apa yang harus dipersiapkan dan lakukan untuk melaksanakan kebijakan publik sehingga apa yang menjadi tujuan dan sasaran kebijakan dapat dicapai sesuai yang diharapkan, yaitu implementasi kebijakan kartu Indonesia pintar dalam upaya pemerataan pendidikan.

Hal ini sesuai dengan pernyataan (Rohman, 2014) implementasi adalah suatu aktifitas yang dimaksudkan untuk mengoperasikan sebuah program. Ada tiga pilar aktifitas dalam mengoperasikan program tersebut, yakni a) pengorganisasian, b) interpretasi dan c) aplikasi. Lebih lanjut lagi, (Rohman, 2014), pengorganisasian meliputi sasaran, sosialisasi, dan sumber daya.

Berangkat dari penjelasan diatas, maka penelitian mengenai implementasi kebijakan kartu Indonesia pintar dalam upaya pemerataan pendidikan adalah penting dan mendesak untuk dilakukan karena hasil dari penelitian ini dapat dijadikan media evaluasi dalam penyempurnaan implementasi kebijakan kartu Indonesia pintar.

Dari uraian diatas, maka penelitian ini akan membahas dua hal, yaitu implementasi kebijakan kartu Indonesia pintar dan implementasi kebijakan kartu Indonesia pintar dalam upaya pemerataan pendidikan.

\section{METODE}

Penilitian ini menggunakan pendekatan kualitatif deskriptif dengan jenisstudikasus. Lokasi penelitian yang digunakan yaitu di SD Negeri Badal II Badal-Ngadiluwih. Teknik pengumpulan data yang digunakan yaitu melalui observasi, wawancara, dan dokumentasi. Informan dalam penelitian ini berjumlah 5 orang, yang terdiri dari: kepala sekolah, seorang guru pengurus kebijakan kartu Indonesia pintar, peserta didik penerima kartu Indonesia pintar dan orang tua peserta didik penerima kartu Indonesia pintar.

Analisis data menggunakan teknik analisis (Mattew \& Hubberman, 1992) yang meliputi proses: kondensasi data (penggabungan dan penguatan data), penyajian data serta penarikan kesimpulan dan verifikasi.

Uji keabsahan data yang digunakan yaitu: uji kredibilitas (melalui triangulasi sumber dan teknik), uji transferability (melalui penyusunan hasil penelitian secara rinci, jelas, sistematis dan dapat dipercaya), uji dependability (melalui audit keseluruhan proses penelitian), dan uji confirmability (melalui publikasi hasil peneltian).

\section{HASIL DAN PEMBAHASAN}

Hasil penelitian yang dipaparkan merupakan hasil analisis dan telah melalui uji validitas data. Dimana dalam pembahasan ini akan membahas dua hal, yaitu implementasi kebijakan kartu Indonesia pintar dan implementasi kartu Indonesia pintar dalam upaya pemerataan pendidikan.

\section{Implementasi Kebijakan Kartu Indonesia Pintar}

Implementasi kebijakan kartu Indonesia pintar dapat dilihat dari buku pedoman pelaksanaan kartu Indonesia pintar yang meliputi pengertian, landasan hukum, tujuan, sasaran, besaran dana, sumber pembiayaan, pemanfaatan dana, mekanisme penetapan dan penyaluran dana, mekanisme pengambilan kartu Indonesia pintar, tugas dan tanggung jawab sekolah.

Dari beberapa aspek yang telah disebutkan dalam buku pedoman pelaksanaan kartu Indonesia pintar tersebut, peneliti tidak mengambil keseluruhan dari aspek-aspek di atas, akan tetapi peneliti lebih menitik beratkan pada lima aspek dari yang telah disebutkan di atas untuk dijadikan pedoman dalam mengimplementasikan kebijakan kartu Indonesia pintar, antara lain sebagai berikut:

Pertama, aspek sasaran. Sasaran kartu Indonesia pintar adalah anak berusia 6 sampai dengan 21 tahun yang 
merupakan:1) penerima BSM 2014 pemegang KPS; 2) siswa/anak dari keluarga pemegang KPS/ KKS yang belum menerima BSM 2014; 3) siswa/anak dari keluarga peserta Program Keluarga Harapan (PKH) non KPS; 4) siswa/anak yang berstatus yatim piatu/yatim/piatu dari Panti Sosial/Panti Asuhan; 5) siswa/anak yang terkena dampak bencana alam; 6) anak usia 6 sampai dengan 21 tahun yang tidak bersekolah (drop out) yang diharapkan kembali bersekolah; 7) siswa/anak dari keluarga miskin/rentan miskin yang terancam putus sekolah. Dari hasil pengamatan dan wawancara dengan pihak sekolah, fakta di lapangan menunjukkan bahwa penerima kartu Indonesia pintar di SD Negeri Badal II sudah memenuhi setidaknya satu dari yang telah disebutkan di atas, yaitu siswa penerima kartu Indonesia pintar adalah siswa dari keluarga pemegang KPS dan KIS.

Menurut Tim Nasional Percepatan Penanggulangan Kemiskinan (TNP2K) program Indonesia pintar melalui KIP adalah pemberian bantuan tunai pendidikan kepada seluruh anak usia sekolah (6-21 tahun) yang berasal dari keluarga pemegang Kartu Keluarga Sejahtera (KKS) atau yang memenuhi kriteria yang telah ditetapkan sebelumnya. Program Indonesia pintar melalui KIP merupakan penyempurnaan dari Program Bantuan Siswa Miskin (BSM) sebelumnya. Selanjutnya, Peraturan Menteri Pendidikan dan Kebudayaan Republik Indonesia Nomor 12 Tahun 2015, program Indonesia pintar yang selanjutnya disebut PIP adalah bantuan berupa uang tunai dari pemerintah yang diberikan kepada peserta didik yang orang tuanya tidak dan atau kurang mampu membiayai pendidikannya, sebagai kelanjutan dan perluasan sasaran dari program Bantuan Siswa Miskin (BSM). Peserta didik adalah anggota masyarakat yang berusaha mengembangkan potensi diri melalui proses pembelajaran yang tersedia pada jalur, jenjang, dan jenis pendidikan tertentu. Kartu Indonesia pintar, yang selanjutnya disebut KIP adalah kartu yang diberikan kepada anak dari keluarga pemegang Kartu Perlindungan
Sosial (KPS)/ Kartu Keluarga Sejahtera (KKS) sebagai penanda atau identitas untuk mendapat manfaat PIP.

Dalam hal ini, melihat dari beberapa kriteria sasaran penerima kartu Indonesia pintar, maka dapat disimpulkan bahwa sasaran penerima kartu Indonesia pintar tersebut sudah memenuhi setidaknya satu dari beberapa kriteria sasaran penerima kartu Indonesia pintar yang telah disebutkan di atas. Sehingga pada simpulannya, dapat dikatakan bahwa di SD Negeri Badal II telah mengimplementasikan kartu Indonesia pintar, yaitu pada aspek sasaran.

Kedua, besaran dana KIP. Besaran dana KIP diberikan per peserta didik dari masing-masing direktorat teknis, untuk Sekolah Dasar (SD) / Paket A: 1) peserta didik kelas I,II,III,IV dan V tahun pelajaran 2016/2017 diberikan dana untuk satu tahun sebesar Rp. 450.000,-; 2) peserta didik kelas VI tahun pelajaran 2016/2017 diberikan dana untuk satu semester sebesar Rp. 225.000,-; 3) peserta didik kelas I tahun pelajaran 2016/2017 diberikan dana untuk satu semester sebesar Rp. $225.000,-$. Dari hasil penelitian menunjukkan bahwa, Besaran dana kartu Indonesia pintar di SD Negeri Badal II sebesar Rp. 450.000,bagi siswa penerima kartu Indonesia pintar yang masih aktif bersekolah di SD Negeri Badal II dan sebesar Rp. 225.000,- bagi siswa kelas $\mathrm{VI}$ yang telah lulus dan pencairan dana masih dilakukan di SD Negeri Badal II.

Ketiga, pemanfaatan dana kartu Indonesia pintar. Program KIP ditujukan untuk membantu biaya pribadi peserta didik agar dapat terus melanjutkan pendidikannya sampai selesai jenjang pendidikan menengah. Dana bantuan diberikan langsung kepada siswa dengan untuk pemanfaatan sebagai berikut: a) pembelian buku dan alat tulis sekolah; b) pembelian pakaian dan perlengkapan sekolah (sepatu, tas, dll); c) transportasi siswa ke sekolah; d) uang saku siswa ke sekolah; e) biaya kursus/les tambahan. Hasil penelitian menunjukkan bahwa pemanfaatan dana kartu Indonesia pintar di SD Negeri Badal II sudah sesuai dengan apa yang telah disebutkan di atas. Namun, selain yang telah disebutkan di atas dari pihak sekolah juga menganjurkan untuk 
menabung dan diwajibkan memberikan sumbangan seikhlasnya. Hasil dari sumbangan tersebut nantinya akan diberikan pada siswa di SD Negeri Badal II yang tidak memperoleh kartu Indonesia pintar tetapi kurang mampu dan benarbenar membutuhkan, yaitu sebesar Rp. 100.000,- per siswa. Lebih lanjut lagi ibu Suprapti, kepala sekolah SD Negeri Badal II,Dari hasil evaluasi, ada siswa penerima kartu Indonesia pintar yang tidak menabung padahal dana KIP sudah cair. Namun, sebagian besar banyak yang menabung.

Keempat, mekanisme pengambilan dana kartu Indonesia pintar. Untuk mekanisme pengambilan dana kartu Indonesia pintar khusus peserta didik paket A/B tidak diwajibkan membawa dokumen biodata yang berisi NISN, menandatangani bukti penerimaan dana PIP yang disediakan oleh lembaga penyalur, untuk siswa SD, SMP, dan SMK yang belum memiliki KTP, pengambilan dana harus didampingi minimal satu orang guru/orang tua/wali, bagi penerima KIP yang menggunakan TabunganKu hanya dapat dicairkan oleh bersangkutan sesuai dengan identitas yang tertulis pada buku tabungan, serta bagi penerima KIP yang menggunakan virtual account dan berada di daerah yang sulit untuk mengakses ke lembaga penyalur (tidak ada kantor lembaga penyalur di kecamatan sekolah/tempat tinggal peserta didik sedangkan biaya transport pengambilan lebih besar dari bantuan yang akan diterima), maka pengambilan dana KIP dapat diambil secara kolektif dengan dikuasakan kepada kepala sekolah/kepala lembaga pendidikan atau bendahara sekolah/bendahara lembaga pendidikan dengan syarat/ketentuan pengambilan kolektif sebagai berikut: a. surat kuasa kolektif dari orang tua siswa penerima KIP dengan melampirkan dokumen persyaratan pengambilan sesuai ketentuan; b. sekolah/lembaga pendidikan menyampaikan surat permohonan pencairan kolektif ke dinas pendidikan kabupaten/kota; c. dinas pendidikan kabupaten/kota menerbitkan surat persetujuan pengambilan dana kolektif hanya diberikan kepada sekolah/lembaga pendidikan, tembusan disampaikan kepada direktorat teknis terkait; d. kepala sekolah yang telah menerima rekomendasi harus membuat Surat Pertanggungjawaban Mutlak (SPTJM) pengambilan dana KIP 2015 secara kolektif yang ditandatangani penerima kuasa bermaterai; e. Penerima kuasa harus menunjukkan identitas seperti KTP atau SIM asli pada saat pengambilan dana secara kolektif; f. Surat keterangan kepala sekolah/ketua lembaga; g. Foto copy halaman biodata raport masing-masing siswa. Dana yang sudah dicairkan oleh penerima kuasa harus segera diberikan kepada siswa penerima yang bersangkutan paling lambat 5 (lima) hari kerja setelah pencairan kolektif, dan pelaporan pencairan kolektif dilakukan paling lambat 10 (sepuluh) hari kerja setelah pencairan kolektif ke Dinas Pendidikan Kabupaten/Kota. Pengambilan dana untuk siswa SD,SMP, dan SMK dapat diambil pada tanggal 5 sampai dengan 24 setiap bulannya; Minimal saldo pada rekening tabungan adalah sebesar Rp.0,-. Dari hasil penelitian dan wawancara dengan kepala sekolah dan pengurus kebijakan kartu Indonesia pintar di SD Negeri Badal II, yaitu ibu Suprapti dan bapak Sugeng serta orang tua dari siswa penerima kartu Indonesia pintar, bapak Syamsul Hadi, menunjukkan bahwa mekanisme pengambilan dana kartu Indonesia pintar sudah berdasarkan apa yang telah dipaparkan di atas.

Kelima, tugas dan tanggung jawab sekolah. Tugas dan tanggung jawab sekolah, yaitu menseleksi dan mengusulkan siswa calon penerima dana KIP dengan pertimbangan siswa berkelainan fisik, siswa korban musibah berkepanjangan,siswa dari orang tua terkena PHK,siswa di daerah konflik sosial,siswa dari keluarga terpidana, siswa dari lembaga penyelenggara pendidikan yang berada di Lembaga Pemasyarakatan (LAPAS),siswa miskin memiliki lebih dari 3 (tiga) saudara tinggal serumah; menyampaikan informasi kepada siswa penerima kartu Indonesia pintar bahwa dana KIP telah siap diambil; membuat surat keterangan kepala sekolah sebagai persyaratan pengambilan dana oleh siswa di lembaga penyalur; memberikan pengarahan kepada siswa penerima dana KIP perihal ketentuan pemanfaatan dana; memantau proses pengambilan/pencairan dana KIP di 
lembaga penyalur; sekolah wajib menerima pendaftaran anak usia sekolah (6 sampai dengan 21 tahun) yang tidak bersekolah dari keluarga pemegang KPS/KKS sebagai calon peserta didik/warga belajar untuk diusulkan sebagai calon penerima dana KIP. Dari hasil pengamatan dan wawancara dengan pihak sekolah, dapat disimpulkan bahwa mengenai tugas dan tanggung jawab sekolah di SD Negeri Badal II belum sepenuhnya melakukan tugas dan tanggung jawabnya.

\section{Implementasi Kebijakan Kartu Indonesia Pintar dalam Upaya Pemerataan Pendidikan}

Menurut Kamus Besar Bahasa Indonesia (KBBI), kata pemerataan berasal dari kata dasar rata, yang berarti: 1) meliputi seluruh bagian, 2) tersebar kesegala penjuru, dan 3) sama-sama memperoleh jumlah yang sama. Sedangkan kata pemerataan berarti proses, cara, dan perbutan melakukan pemerataan. Jadi dapat disimpulkan bahwa pemerataan pendidikan adalah suatu proses, cara dan perbuatan melakukan pemerataan terhadap pelaksanaan pendidikan, sehingga seluruh lapisan masyarakat tanpa memandang siapapun mereka dapat merasakan pelaksanaan pendidikan. Sementara itu yang dimaksudkan dengan pemerataan dan keadilan ini mengacu kepada rumusan atau batasan Bronfenbrenner (Jones, 1980), yang dikemukakan sebagai berikut :

“. . . equity to mean social justice, or

fairness. It refers to as subjective and ethical judgement. Equality refers to the pattern of distribution of something, such as income or education, for example. Equality is more objective, descritive term."

Lebih lanjut lagi, (Rifai, 2011), pemerataan pendidikan mencakup dua aspek penting, yaitu equality dan equity. Equality atau persamaan mengandung arti kesempatan untuk memperoleh pendidikan. Sedangkan, equity bermakna keadilan dalam memperoleh kesempatan pendidikan yang sama di antara berbagai kelompok dalam masyarakat. Akses terhadap pendidikan yang merata berarti semua penduduk usia sekolah telah memperoleh kesempatan pendidikan.
Sementara itu, akses terhadap pendidikan telah adil jika antar-kelompok bisa menikmati pendidikan secara merata.

Hasil penelitian menunjukkan bahwa di SD Negeri Badal II sudah melakukan dua aspek penting dalam pemerataan pendidikan, yaitu equality pada implementasi kebijakan kartu Indonesia pintar di SD Negeri Badal II dan equity pada pemberian bantuan sebesar Rp. 100.000,bagi siswa yang tidak menerima kartu Indonesia pintar tetapi kurang mampu dan benar-benar membutuhkan, bantuan tersebut diperoleh dari siswa penerima kartu Indonesia pintar yang diwajibkan memberi sumbangan seikhlasnya setelah dana dari kartu Indonesia tersebut cair.

Selain kedua aspek di atas, adanya sosialisasi kebijakan kartu Indonesia pintar juga menjadi faktor pendorong tercapainya pendidikan yang merata di Indonesia.

\section{KESIMPULAN}

Kesimpulan dari penelitian ini menunjukkan bahwa: implementasi kebijakan kartu Indonesia pintar melalui buku pedoman pelaksanaan kartu Indonesia pintar, maka dapat di ukur melalui lima aspek, yaitu sasaran, besaran dana, pemanfaatan dana, mekanisme pengambilan dana KIP serta tugas dan tanggung jawab sekolah. Adapun implementasi kebijakan kartu Indonesia pintar dalam upaya pemerataan pendidikan, maka dapat dilihat dari dua aspek penting dalam pemerataan pendidikan, yaitu equality dan equity. Selain itu, sosialisasi dari kebijakan kartu Indonesia pintar.

\section{DAFTAR RUJUKAN}

Edward, I. (1980). Implementing Public Policy. Washington D.C: Congressional Quarterly Inc.

Jones, S. P. (1980). Education and Equality in Developing Countries. Planning Education and Development, 1, 157186.

Mattew, M. B., \& Hubberman, M. (1992). Anslisis Data Kualitatif. Jakarta: UI Press.

Rifai, M. (2011). Politik Pendidikan Nasional. Yogyakarta: Ar Ruzz Media. 
Rohman, A. (2014). Kebijakan Pendidikan.

Yogyakarta: Aswaja Pressindo.

Saroni, M. (2013). Pendidikan untuk Orang Miskin Membuka KeranKeadilan dalam Kesempatan Berpendidikan.

Yogyakarta: Ar Ruzz Media.

Supeno, H. (1999). Pendidikan dalam

Belenggu Kekuasaan. Magelang:

Pustaka Paramedia. Magelang:

Pustaka Media. 